\title{
Lifestyle information from YouTube influencers: Some consumption patterns ${ }^{1}$
}

Mike Thelwall, University of Wolverhampton, UK.

Purpose: Despite lifestyle information needs being an important part of our daily lives, little is known about the role of common sources. Whilst magazines and television are traditional providers of lifestyle content, including for fashion, makeup, fitness, and cookery, they have been partly replaced by content-creating online influencers.

Design/methodology/approach: To investigate this new resource, this article analyses comments on the videos of 223 UK female lifestyle influencers on YouTube for information about possible viewing patterns.

Findings: Three quarters of comments are written during the week of the video being published, consistent with videos being consumed with an information browsing function, rather than treated as an information resource to be searched when needed. Commenting on the videos of multiple influencers occurred often, suggesting that many viewers are not loyal to a single influencer. Thus, influencers seem to primarily support active scanning rather than searching for specific information. Typical viewers of UK female lifestyle influencers can therefore expect to accumulate lifestyle ideas and knowledge for potential future use in addition to gaining timely suggestions for near future routine decision making.

Practical implications: Public-facing information professionals, health professionals and counsellors may consider recommending selected videos or influencers to help with lifestyle concerns.

Originality: This is the first large scale study of content-creating influencers as a lifestyle information resource.

Keywords: Lifestyle information; YouTube; Influencers; Branding; Vlogs; Information behaviour

\section{Introduction}

Lifestyle information about personal appearance, family, friendship, eating and living arrangements is essential to the smooth running of daily lives. It is traditionally provided by lifestyle and fashion magazines, television, and radio shows, in addition to word-of-mouth information from friends and advertising. For example, lifestyle magazines are a major source of information about healthy eating (Schneider and Davis, 2010), dietary supplements (Macleod and Anderson, 2018) and exercising during pregnancy (Clarke and Gross, 2004) as well as teaching wider life lessons, such as the need for resilience in difficult circumstances (Gill and Orgad, 2018). These sources are consumerist rather than primarily informational, providing advertising and promoting their own ideal lifestyle standards (Rees, 2019; Small, 2017), in line with their advertising goals (Wolf, 2001). Lifestyle and social information can also be shared through gossip, which is another important information source (Dunbar, 1998; Robbins and Karan, 2020). Nevertheless, lifestyle needs and sources are rarely analysed from an information perspective, with the main exceptions being health-related topics, such as exercise and healthy eating.

\footnotetext{
${ }^{1}$ Thelwall, M. (in press). Lifestyle information from YouTube influencers: Some consumption patterns. Journal of Documentation.
} 
Content-creating social media influencers are a relatively new and popular source of lifestyle information. These influencers produce popular videos, images, and textual content across social media platforms like YouTube, Instagram, and Facebook. Whilst their content provides entertainment, this article focuses on its information provision function. More specifically, it investigates when lifestyle influencer content is consumed (e.g., when the videos are new, as for lifestyle magazines or television shows, or at any time, as for advice books) and how many influencers are consulted by each person. Whilst TV and radio shows until recently had to be watched during their timetabled slots and magazines are typically designed to be up-to-date and disposable, most social media content is relatively permanent and searchable (e.g., through Google) at any time, irrespective of its creation date. Nevertheless, many influencers produce television-like semi-disposable content in the sense of moderate length videos released on a regular schedule with limited lifespan elements, such as reviews of seasonal fashions. Thus, viewers can either watch regularly or sporadically search for videos to satisfy specific needs. Without knowing how lifestyle videos are found and watched, it is more difficult to support people with lifestyle information needs and provide advice to content providers about how to maximise the information value of their videos.

There is no perfect method to investigate how people access lifestyle information from content creating influencers. The major social research methods of surveys, interviews, focus groups and ethnography could all give valuable insights but suffer from sampling issues because viewers could be anywhere in the world, there are ethical issues associated with contacting minors for research (who may form a substantial fraction of the audience), and these methods rely on the ability of people to remember their casual viewing habits. Digital methods exploiting evidence left on the websites of the influencers address these limitations but have other sampling problems, give less rich information, cannot discover users' motivations, and cannot set the viewing act into the life context of users. Nevertheless, this article adopts the digital methods approach for its potential to cover the actions of a much larger number of users than practical for other methods and as useful for an initial "big picture" exploration of a related phenomenon (commenting) that can suggest patterns of information behaviour for viewing. This indirect and shallow approach seems justifiable in the absence of a practical alternative for big picture information.

This article investigates some aspects of temporal patterns and influencer choice for commenting on YouTube UK female lifestyle influencers' videos. YouTube was chosen for pragmatic reasons. It was the second most visited website in the world in February 2021 according to Alexa.com (www.alexa.com/topsites) and is a recognised home of influencers, at least in the UK and USA. Whilst Instagram is also an important site and there are other similar sites in China and elsewhere, YouTube allows automated access to comments, making large-scale analysis possible. The focus is on the UK as a major user of YouTube but with a manageable number of influencers compared to the USA. Female influencers were chosen because women seem to dominate the lifestyle genre in the UK and because male lifestyle influencers seem to typically have narrow channels (e.g., executive suits, body building) (Thelwall and Cash, in press). Comments on videos are analysed rather than the viewers because comments are the only information provided by YouTube about video audiences. The commenters therefore substitute for viewers in this study (an important limitation). Finally, the focus is on temporal and influencer patterns of viewing for pragmatic reasons (the information is available for large scale analysis) and because they are relevant to information seeking patterns, even though indirectly. The discussion section will relate the findings back 
to information seeking. The content of comments is ignored because the typical comment is a complement that is not informative about information seeking (e.g., omg you look gorgeous!), and to allow a focus on aspects of the data that can be analysed with similar quantitative methods. The following exploratory research questions drive the study.

- Q1: Age: Do viewers tend to comment on newer or older videos from UK female lifestyle influencers? Commenting on newer videos would be more consistent with using them to keep up to date rather than using them to find a particular piece of information, for example.

- Q2: Videos: Do viewers tend to comment on multiple videos from UK female lifestyle influencers?

- Q3: Influencer: Do viewers tend to comment on videos from multiple UK female lifestyle influencers?

- Q4: Time: Do viewers tend to comment on videos from UK female lifestyle influencers individually or binge-watch them?

\section{Literature review}

This section reviews lifestyle information behaviour and how lifestyle information can be delivered on YouTube. Whilst there is some research into how, why and when people watch YouTube (e.g., Foster, 2020) and the content of YouTube comments (Thelwall, 2021), none so far seems to focus on general lifestyle information. Given the wide variety of uses of YouTube, from education and news to gaming and cartoons, it does not seem relevant to report general YouTube usage studies. Similarly, it does not seem relevant to report investigations of narrow lifestyle activities on YouTube, such as music seeking and sharing ( $\mathrm{Hu}$, Lee, and Wong, 2010). The issue of temporality has sometimes been addressed in information behaviour research, but usually within active searching contexts (e.g., Beheshti et al., 2015; Solomon, 1997), so this aspect is also not covered.

\section{Everyday or lifestyle information sources: gossip, lifestyle magazines, chat shows}

Although information behaviour research typically focuses on professional and other work contexts, there is also interest in wider "everyday" information behaviour (Harisanty, 2019; Ocepek, 2017; Savolainen, 1995), with health information seeking being particularly important. Lifestyle information is not precisely defined (lifestyle means, "someone's way of living; the things that a person or particular group of people usually do": Cambridge, 2021) and in the current paper it is equated with the topics discussed by lifestyle influencers: primarily fashion, beauty and the home, but excluding influencers providing recipes or home maintenance. It largely excludes work, politics, and medical information.

Information behaviour research recognises many different methods by which people can obtain useful information. A user may search for a fact or piece of information, such as the options available for securing a student loan, with Google or a library system. Alternatively, they may browse relevant sources to discover relevant information, such as the types of things that would be useful to bring to college accommodation. A third strategy is active scanning: continually or periodically checking a specified set of current information sources for relevant information, such as whether new events for college first years had been announced (McKenzie, 2003). Information can also be encountered serendipitously (Agarwal, 2015) from advertising or by accident, such as walking past a sale of music posters suitable for college bedrooms, or by proxy, when someone else provides unsolicited advice (McKenzie, 
2003), such as a local restaurant that they have just visited. Serendipity might also be called passive attention (Wilson, 1997), especially if a person chooses to be in a position to encounter relevant information, without active scanning. For example, someone might enjoy watching lifestyle themed television programs partly in the knowledge that useful ideas might occasionally be revealed.

People obtain information to support lifestyle or everyday life decisions in many ways. Both active information seeking (searching and browsing) and more passive information encountering (the other methods mentioned above) (Erdelez, 1999) are used but the latter may be more common (e.g., in Iceland 2001/2007: Pálsdóttir, 2010). Thus, lifestyle information can be expected to appear at least from active scanning, by proxy and serendipity (McKenzie, 2003). For example, people might scan recent lifestyle magazines for new house ideas or download an informational smartphone app (Ford, et al., 2020) (active scanning), enjoy reading lifestyle magazines partly in the knowledge that they may find useful information (passive attention/serendipity) or randomly read a lifestyle magazine in a dentist's waiting room, noticing something of interest (serendipity). Thus, different people may consume the same resource (e.g., lifestyle magazine, YouTube channel) with a different mix of entertainment and active scanning motivations, and these motivations may influence the extent to which they identify relevant information (Foster and Ford, 2003).

Lifestyle information may also be obtained from friends and acquaintances through chat (serendipity) or by receiving advice (by proxy). Individuals believing that mass media sources do not cater for their needs may rely on friends and acquaintances more (Chatman, 1991). People may also choose their recreational activities partly because of their potential as information sources. For instance, someone might join a parent-and-baby group for its baby socialisation potential but partly in the knowledge that other parents may have relevant experiences to share (e.g., Barros et al., 2008; Windham Stewart, 2016). Of course, information sources can subsequently become friends (e.g., Lloyd and Olsson, 2019).

\section{Lifestyle information on YouTube}

YouTube may fill the friends and acquaintances role in active scanning or serendipity by offering experiences in an informal chatty setting, albeit through a broadcast medium. Also, since influencers may survive with small audiences and represent specific lifestyles (e.g., college student, knitter, party animal, young mother, South Asian dating guru, vegan cook, rich fashionista, transgender) that match the needs or aspirations of different audiences, they may sometimes provide more targeted information than friends (Raun, 2018). Lifestyle influencers' videos can include practical advice around many different topics, including makeup (Ananda and Wandebori, 2016), fashion, beauty (Mardon et al., 2018; Raun, 2018), fitness, health, domestic finance, friendship, relationships, restaurants, cooking (Forchtner and Tominc, 2017), decluttering (Zappavigna, 2019) and minority group lifestyles (Raun, 2018). They can also share intimate personal information, giving insights into the daily life from the perspective of the influencer (Ferchaud et al., 2018). Discussions of major life events, such as childbirth or identity shifts, could also be shared (Haimson et al., 2021). This parallels YouTube's use as an educational resource (Dubovi and Tabak, 2020) and (not always accurate) health information resource (Aydin and Aydin, 2020; Li, Bailey, Huynh, and Chan, 2020). The lifestyle genre is sometimes used by political groups, including a neo-nazi vegan cookery vlog (Forchtner and Tominc, 2017), but the incorporation of politics seems to be rare.

Another advantage of YouTube is that some lifestyle information is embodied (hard to describe in words but understandable by viewing the practice: Olsson and Lloyd, 2017), 
such as how to apply mascara. Some is also three-dimensional, such as what a kitchen looks like after decorating, and is therefore more suited to online video or television than magazines or books. Within YouTube, the "How-to" genre of videos is highly popular (Foster, 2020), and overlaps with the lifestyle topic, especially through makeup tutorials. How-to videos are presumably searched for in response to new problems, although they could also be encountered as one of the weekly videos of a popular influencer.

The lifestyle genre is highly competitive because of the financial rewards of success through brand endorsements and paid reviews. Because of this competition, creative, visual and computing technical expertise is needed to attract subscribers (Bishop, 2019; Riboni, 2017). Most academic research about influencers seems to have focused on the commercial angle, and particularly the practice of brand endorsements and recommendations (Ananda and Wandebori, 2016; Schwemmer and Ziewiecki, 2018). This research has examined, for example, the strategies influencers can use to make their endorsements more persuasive without alienating their audiences (Stubb et al., 2019). This is relevant to lifestyle information behaviour in the sense that it skews the content of successful videos towards commercially viable topics. For example, top makeup influencers may attract larger audiences because their revenue and competition pushes them towards more expensive technology (video equipment and editing software, perhaps with a technical support team) and the need to be more creative to attract and keep an audience.

YouTube videos may also be watched for entertainment even when they have informational content: perhaps someone enjoys the transformation associated with elaborate make-up tutorials without ever intending to wear makeup. From an entertainment perspective, it might be natural to watch YouTube videos in series. For example, someone discovering an influencer might binge watch all their videos from their home page or through their YouTube playlists. Binge watching seems to associate with entertainment-related motivations (Flayelle et al., 2019), and so it is not clear whether it would be common for infotainment products.

\section{Methods}

This study created a list of UK female lifestyle influencers, downloaded the comments on their videos, and used timestamps in videos and comments to produce a range of descriptive statistics. The first stage, identifying UK female lifestyle influencers was achieved by four people browsing YouTube for relevant channels with at least 2000 followers in OctoberNovember 2020. This relatively arbitrary minimum threshold was set to focus on influencers that are at least moderately successful. Manual searches were needed because although YouTube has a Fashion and Beauty channel that showcases lifestyle content from different influencers, the are no comprehensive lists of lifestyle influencers on YouTube and the site does not provide a simple method to filter for this attribute. The final set of 223 influencers was almost certainly incomplete but collectively includes over 8 billion video views, as reported by YouTube.

The YouTube Applications Programming Interface (API) was accessed through the free software Mozdeh (mozdeh.wlv.ac.uk) to download a list of videos from each influencer's YouTube channel, together with their publishing dates, and a list of comments on each video. This occurred from October to November 2020. The data was processed to exclude comments that influencers posted to their own videos, since they are information producers in this context. The prevalence of these self-comments varied considerably, with some influencers replying to most commenters and others never responding. The data was aggregated as 
necessary using programs written and added to the free software Webometric Analyst (YouTube tab) to produce frequency graphs for the comment data.

To protect the anonymity of commenters (Wilkinson and Thelwall, 2011), the illustrative quotes given in this article are all made-up but similar to genuine comments.

\section{Results}

The data collection found 5,660,702 YouTube users that had written 21,908,453 comments on 76,923 videos from the 223 YouTube female influencer channels examined. Most of these users $(60 \%)$ only commented on a single video from this set, but one commented on 4250 different videos. The number of commenters commenting on $\mathrm{n}$ videos decreases very rapidly with $n$, approximately following the characteristic power law shape (semi-logarithmic graph in Figure 1: see: Pennock et al., 2002). This power law shape means that posting comments to multiple videos is a rare activity and commenting on many videos is extremely rare. For example, only $5 \%$ of the commenters posted on more than ten videos from these influencers, and $0.15 \%$ commented on more than 100 videos. Thus, commenting on many videos is extremely rare compared with commenting on one.

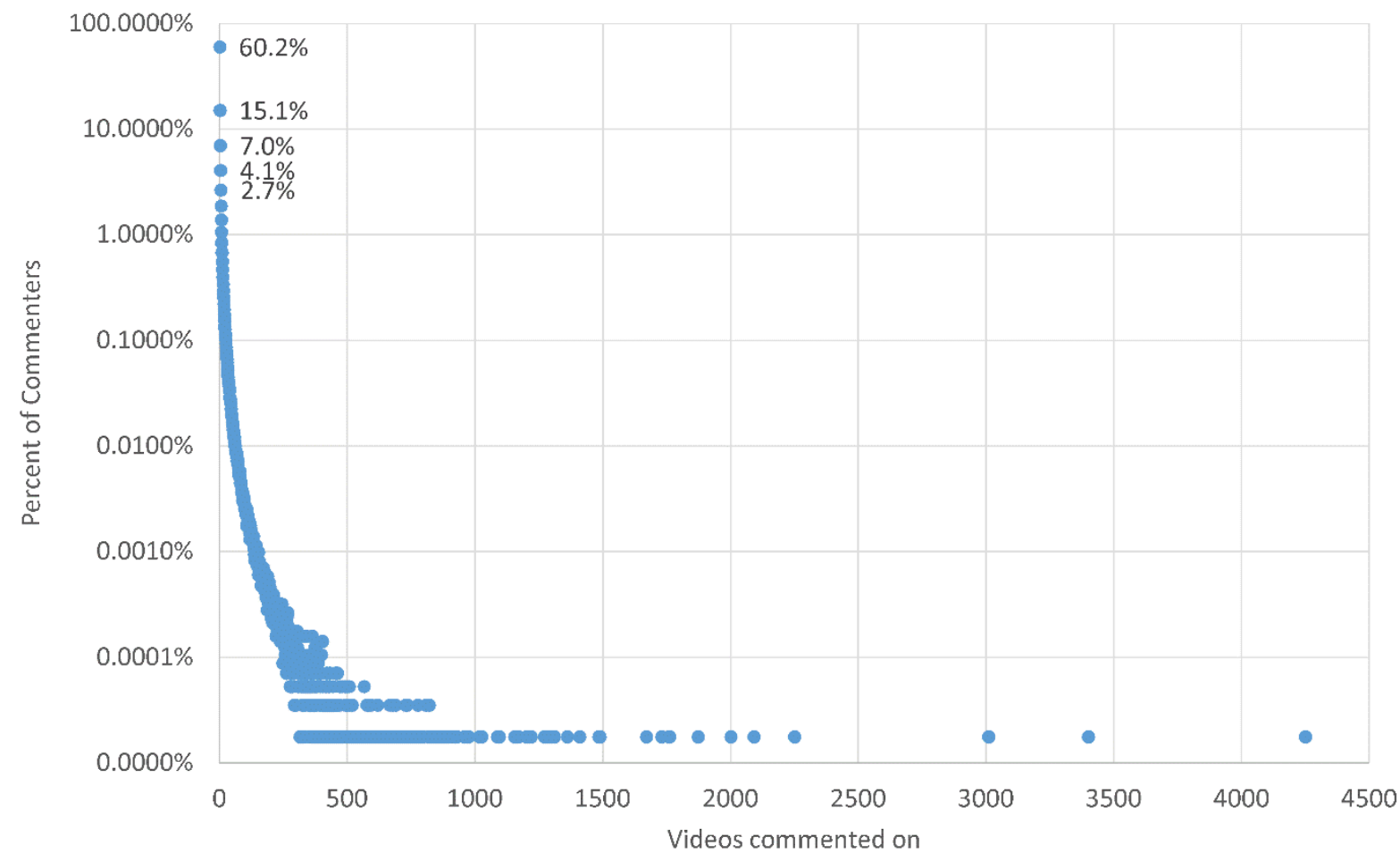

Figure 1. The number of different videos commented on by the commenters. The y-axis follows a logarithmic scale.

Three quarters $(74.5 \%)$ of the commenters only wrote on videos from one influencer from this set of 223, with the number of channels commented on again following a power law (Figure 2). The $74.5 \%$ includes the $60.4 \%$ of commenters that wrote a single comment, so most commenters that wrote on at least two videos commented on multiple channels from this set. This suggests that more active commenters are typically not exclusive to one influencer. 


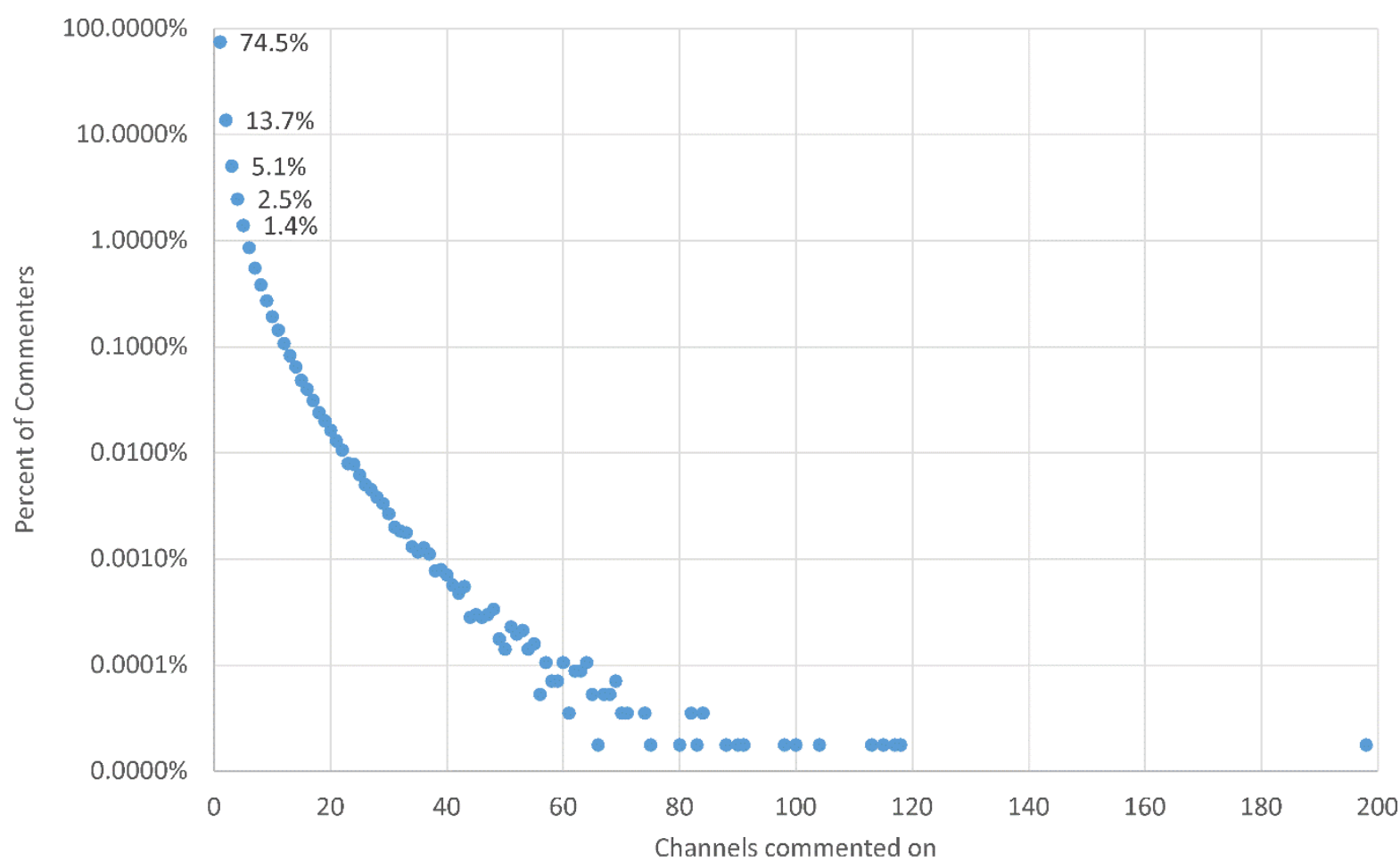

Figure 2. The number of different channels commented on by the commenters. The $y$-axis follows a logarithmic scale.

Most comments (57\%) were posted within 24 hours of the video publication time and three quarters (75\%) within one week, with the gap frequency decreasing again following a power law shape (double logarithmic graph: Figure 3). The shape has a hook (normal for power law variants: Thelwall and Wilson, 2016) at the right-hand side, with the longest gap being 13.6 years. The 13.6-year gap reflects the earliest start date of any of the influencers, and because of this the linear (broomstick) power law pattern breaks and bends downwards on the right of Figure 3. Thus, there is a very strong tendency to comment on recent videos, despite the availability of some decades-old videos from influencers (like Zoella) that continue to attract followers. 


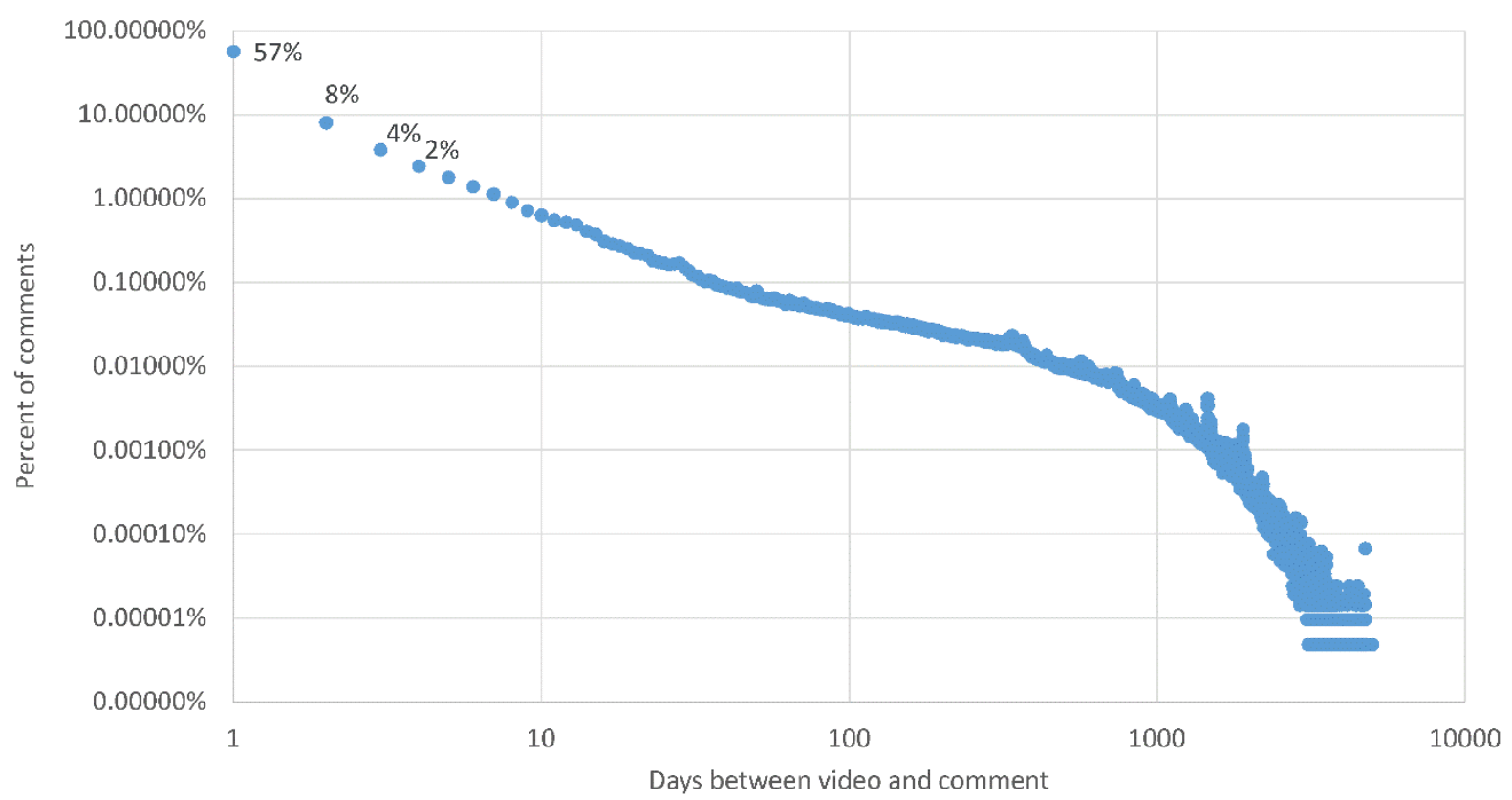

Figure 3. The maximum gap between each comment and video publication dates. commented on by the commenters. Both axes follow logarithmic scales.

When someone comments on multiple videos from the 223 influencers, the comment is not made within an hour of any other comment from them on videos from the 223 influencers in two thirds (74\%) of cases (Figure 4). In even more cases (86\%), the comment is not within an hour of comments from them on other videos from the same influencer. Thus, at least within this set of 223 influencers, burst commenting in the sense of commenting on consecutive videos in a chain with under an hour between comments is a minority activity but not rare. If the maximum permissible gap is increased to 1 day, so the commenter is commenting on videos daily, then longer bursts are more common. For example, only $18 \%$ of comments were not posted within 24 hours of another comment from the same commenter on videos from the 223 influencers. Similarly, $47 \%$ of comments were not posted within 24 hours of another comment from the same commenter on the same influencer. Recall that the statistics in this paragraph concern the $40 \%$ of commenters that commented on multiple videos.

The frequency of the number of videos in a burst decreases following a power law shape in all four cases examined, except for the two parallel dotted lines in the lower right hand corner (Figure 4). These shapes do not break the power law expectation (i.e., a hooked broomstick shape more like Figure 3 ) at a probabilistic level because they reflect comments rather than bursts. For example, a burst of length 8830 is counted 8830 times, once per comment, so the longest bursts are rarest but carry the highest individual weight. 


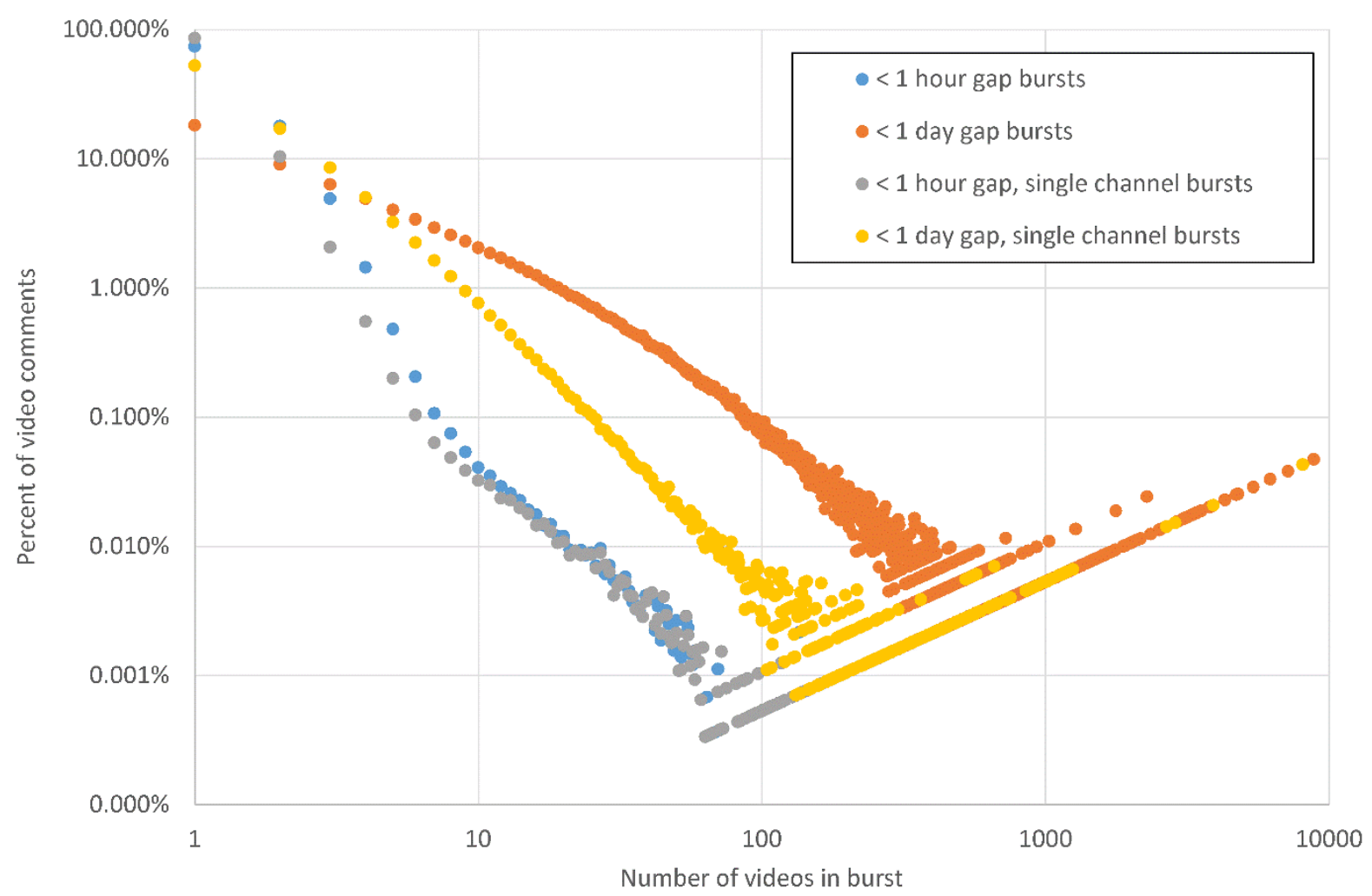

Figure 4. Video presence within watching bursts, with four different burst definitions. Both axes follow logarithmic scales. Only comments from users making multiple comments are included.

\section{Discussion}

This section first discusses the results in terms of commenting and then attempt to speculate about the implications for lifestyle information consumption from YouTube influencers. As a reminder of the main limitations of the methods used, the data concerns a large but incomplete set of UK female YouTube influencers and it excludes influencers with few followers and videos that have been deleted. There are likely to be gender, national, and platform differences in the consumption of influencer videos and so the results may not apply to dissimilar contexts (e.g., male lifestyle influencers on Tencent in China, nonbinary lifestyle influencers on Instagram in Nigeria). The results are also only about YouTube commenters, which probably form a tiny minority of all users.

From the perspective of interpretation, another major limitation is that the data is not directly about information use. Although some comments mention information or contain questions (e.g., "Since you like dosas you should try Masala Spice in Hackney", "Where is the cheapest place to try that?") many give simple positive feedback (e.g., "Gorgeous!!!", "So jealous of your lush kitchen"). Adding to this the fact that commenters might have different motivations and use patterns than typical YouTube viewers, the evidence is far removed from being about the information behaviour of typical viewers. Thus, although the evidence is quantitative and on a huge scale, it is not directly about information behaviour and its value to information seeking is in giving evidence-based suggestions about how information behaviour related to lifestyle influencers may work. 


\section{Patterns of commenting}

The results show that within the span of the 223 UK female influencers, comments are usually one-off $(60.2 \%)$, with extensive commenting being very rare. Because of this, commenters usually comment to only one influencer (74.5\%), although most $(64.0 \%)$ people commenting on multiple videos comment on multiple influencers. From the perspective of video viewing, this data suggests, but does not prove, that viewers tend to watch multiple similar influencers rather than being primarily loyal to one. This is based on the assumption people commenting only once have not revealed anything about their viewing patterns. If this assumption is not accepted, however, then it is still true that a quarter of commenters visit multiple similar influencers and so strict influencer loyalty is far from universal. In other words, it seems likely that it is common for UK female lifestyle video watchers to visit multiple influencers. Nevertheless, patterns for people that watch but do not comment on videos might be different.

The results show that comments are usually written on the day that a video is posted, with comments on old videos being extremely rare. Whilst it is possible that people are most likely to comment on a new video because they are more likely to get a reply or Like if they are early, this suggests that influencer videos are typically consumed as contemporary information. This fits with some content (seasonal fashion and makeup reviews, life updates) but not with other aspects (recipes, financial advice, generic makeup tutorials, advice about coping with personal issues). Many influencers have a regular posting schedule and subscribers can expect a YouTube notification when a new video is released, so this publicity encourages early viewing. Nevertheless, influencers seem to keep all or many videos live, occasionally produce tutorials with clear long term value, have a long term welcome video in their home page, and may curate viewing lists of videos fitting different themes. Thus, they provide support for viewing older videos. Whilst this support does not seem to be the main source of commenting or viewing, it may serve to generate viewer loyalty or cater to loyal viewers. Influencers seem to be socially attractive people that make an entertaining product so it would be possible for viewers to watch their old videos for entertainment even when the information was obsolete (e.g., last year's summer clothes reviewed). Thus, the contemporary viewing data tends to confirm that the information component of lifestyle videos is important to viewers.

In terms of bursts, commenting on multiple videos with gaps of less than an hour is extremely rare, even for people writing multiple comments. In contrast, commenting on multiple videos within a day is a substantial minority activity. This might occur, for example, for people that follow multiple influencers or that watch several videos to satisfy a particular information need (e.g., multiple influencers' reviews of the same new product or fashion line). These results nevertheless suggest that binge watching in the sense of watching many videos consecutively from the same influencer (e.g., to systematically watch all their back catalogue) is almost absent. Presumably influencer videos lack the dramatic build-up and cliff-hangers of binge watched television dramas and are therefore less addictive.

The consumption of recent content suggests that information encountering is more important for lifestyle videos than searching, confirming an earlier lifestyle information survey (Pálsdóttir, 2010). This seems likely to be part of an active scanning informal strategy, although some may watch influencers for pure entertainment or for its social value, in which case any information encountered would be serendipitous. Nevertheless, it is possible that users actively search for targeted information and only access recent YouTube videos because 
these are ranked more highly by the YouTube and Google search algorithms (YouTube mainly reports recent videos in category listings: Foster, 2020).

\section{Graph shapes}

All the graphs followed the straight-line shape on a double logarithmic graph that indicates a pure power law or a hooked version of it that could be a modified power law or discretised logarithmic distribution. Some graphs are illustrated here with only one axis logarithmic (Figures 1 and 2), but double logarithmic axis versions are available in the online supplement (https://doi.org/10.6084/m9.figshare.14525538). The fan tail in the bottom right-hand side of the graphs is also characteristic of the power law and alternative distributions. The power law and its hooked variant are consistent with a positive feedback mechanism partly driving the numbers, where entities are rewarded for high scores (Pennock et al., 2002). This is encapsulated in the phrase "rich get richer". Whilst the shapes alone do not prove that richget-richer positive feedback mechanisms exist and cause the shapes, they suggest this as a possibility. This is discussed in the next steps.

The power law shape in Figure 1 suggests that commenters are rewarded somehow for commenting on videos, with their reward increasing disproportionately much compared to the number of videos. A possible feedback mechanism here is recognition: frequent commenters might become recognised by influencers who then give them more frequent replies, personalised replies or perhaps even send private thank you messages. In at least one case, an audience member was invited to join the influencer in a meet-the-fans video on the channel, which would serve as a recognition reward and might incentivise others to become known through frequent commenting. Alternatively, frequently posting on an influencer's videos might gain recognition and comment-based interactions with other audience members, helping to build audience community spirit.

The power law shape in Figure 2 suggests that commenters are rewarded for commenting on multiple channels, with this reward increasing disproportionately much compared to the number of different channels. The influencer feedback mechanism of Figure 1 does not apply here, but a person commenting on more influencers might get rewards in the form of recognition by other audience members following similar multiple influencers or through being able to write more appropriate or informative comments on each influencer's videos through their knowledge of others.

The power law shape in Figure 3 suggests that commenters are rewarded for commenting more frequently, with this reward increasing disproportionately much compared to the frequency of the posts. This may have the same recognition cause as Figure 1 since more comments indicates that they must appear more frequently. Similarly, the power law shape in Figure 4 suggests that commenters are disproportionately rewarded for commenting in longer bursts of videos. This may also be due to recognition, assuming that commenters become more recognised if they post consistently over a longer period of time, in addition to needing to post more to get longer bursts of commenting.

In addition to the above feedback mechanisms, there may be internal positive feedback mechanisms within audience members. For example, viewers might have a perception of being part of a community through active commenting increasing the pleasure of commenting, or might feel a virtual connection with the influencer, type of parasocial relationship (Ferchaud, et al., 2018).

As suggested by the above discussion, the most likely feedback mechanisms do not seem to be related to information seeking. Information seeking feedback mechanisms are 
possible, however. For example, watching more videos might lead to increasing knowledge and expertise about lifestyle issues for some people, who may get lifestyle-related rewards for applying this expertise (e.g., complements from friends, improved social life, greater personal satisfaction with physical appearance when going out), leading them to seek it more assiduously in the confidence that the knowledge generates positive life outcomes. More concretely, a person watching the videos might learn how to apply makeup and might need to spend increasingly much money and time investigating makeup to improve their increasingly specialist expertise (money spent on makeup varies greatly between women that use it: Mafra et al., 2020).

\section{Conclusions}

The comment results are consistent with YouTube influencer videos being watched primarily shortly after they are released, rather than being binge-watched or selected based on content. Users also seem to be willing to visit different influencers. The results therefore suggest that YouTube influencer videos providing a resource for lifestyle active scanning, in a similar way to lifestyle and fashion magazines. Whilst this does not prove that this is the best way to watch influencers and some of their videos have lasting value, it suggests that keeping up to date with one or a few appropriate influencers is the default viewing strategy.

Given the huge audience of female lifestyle influencers in the UK ( 8 billion views for the influencers analysed here), the results suggest that a substantial (presumably mainly female and younger) fraction of UK society is getting regular lifestyle information from influencers on YouTube, and presumably similar information from Instagram. The current article's shallow quantitative perspective does not allow conclusions about the societal implications of this fact, but some issues are worth raising for discussion, as follows, because the lifestyle informational content of videos seems rarely to be discussed in academic research.

From a critical perspective, lifestyle influencers seem to be consumerist, often reviewing products. Moreover, lifestyle magazines in the USA have been criticised for promoting constraining female ideals in the service of advertisers (Wolf, 2001) and the same may be true for influencers since many lifestyle channels have a relationship with brands as part of their business strategy, and some use filters to enhance their appearance or that of a product. Lifestyle influencer audiences might be unable to afford these products and might feel social pressure to buy them. On the other hand, lifestyle influencers can give a much more rounded picture of female life, with both positives and negatives and self-reflection. For example, whilst a glossy magazine advert might show an immaculately dressed supermodel wearing a product in unattainably airbrushed perfection, an influencer might show step-bystep how the same product transforms her appearance and include some criticisms. In another video, the same influencer might discuss weight issues, sometimes feeling ugly, or mental health concerns. In addition, influencers sometimes include meta-discussions and analyse ethical issues, so they seem to give a more nuanced and realistic picture of life.

Users approaching health professionals or councillors and perhaps also information professionals like librarians for help on lifestyle issues may have their problem best solved by pointing them to appropriate content from lifestyle influencers. Content from lifestyle influencers might be particularly useful for those that are unable to access appropriate lifestyle information through other sources or that enjoy consuming it in the informal chatty and personal environment of an influencer vlog. In theory, lifestyle influencer content may also be useful for more personal lifestyle topics, such as underage drinking, bullying, tampon 
use, masturbation, or period sex, where the authority of peer influencers and the tone of their message may be essential to the credibility of the advice. This assumes that the information provided by female lifestyle influencers is appropriate and unproblematic. Audience comments provide a partial safeguard against problematic content; for example, many fan comments on one video strongly criticised the influencer's boyfriend for incorrect mask wearing (during Covid-19 social distancing), which she repeatedly apologised for in replies. Nevertheless, professional judgement may be needed to check that content is ageappropriate (e.g., in schools: Gruet, 2021) and otherwise suitable before recommending it.

\section{References}

Agarwal, N. K. (2015). "Towards a definition of serendipity in information behaviour", Information Research: An International Electronic Journal, Vol. 20 No. 3, pp. n3.

Ananda, A. F., and Wandebori, H. (2016). "The impact of drugstore makeup product reviews by beauty vlogger on YouTube towards purchase intention by undergraduate students in Indonesia", In International Conference on Ethics of Business, Economics, and Social Science, Vol. 3 No. 1, pp. 264-272.

Aydin, M. F., and Aydin, M. A. (2020). "Quality and reliability of information available on YouTube and Google pertaining gastroesophageal reflux disease", International Journal of Medical Informatics. Vol. 137 paper 104107.

Barros, M., Kitson, A., and Midgley, N. (2008). "A qualitative study of the experience of parents attending a psychoanalytically informed parent-toddler group", Early Child Development and Care. Vol. 178 No. 3, pp. 273-288.

Beheshti, J., Cole, C., Abuhimed, D., and Lamoureux, I. (2015), "Tracking middle school students' information behavior via K uhlthau's ISP Model: Temporality", Journal of the Association for Information Science and Technology, Vol. 66 No. 5, pp. 943-960.

Bishop, S. (2019). "Managing visibility on YouTube through algorithmic gossip", New Media \& Society, Vol. 21 No. 11-12, pp. 2589-2606.

Cambridge (2021). "Lifestyle", https://dictionary.cambridge.org/dictionary/english/lifestyle

Chatman, E. A. (1991). "Life in a small world: Applicability of gratification theory to information-seeking behavior", Journal of the American Society for Information Science. Vol. 42 No. 6, pp. 438-449.

Clarke, P. E., and Gross, H. (2004). "Women's behaviour, beliefs and information sources about physical exercise in pregnancy", Midwifery. Vol. 20 No. 2, pp. 133-141.

Dubovi, I., and Tabak, I. (2020). "An empirical analysis of knowledge co-construction in YouTube comments", Computers \& Education. Vol. 156, pp. 103939.

Dunbar, R., (1998). Grooming, gossip, and the evolution of language. Cambridge, MA: Harvard University Press.

Erdelez, S. (1999). "Information encountering: It's more than just bumping into information", Bulletin of the American Society for Information Science and Technology, Vol. 25 No. 3, pp. 26-29.

Ferchaud, A., Grzeslo, J., Orme, S., and LaGroue, J. (2018). "Parasocial attributes and YouTube personalities: Exploring content trends across the most subscribed YouTube channels", Computers in Human Behavior. Vol. 80, pp. 88-96.

Flayelle, M., Canale, N., Vögele, C., Karila, L., Maurage, P., and Billieux, J. (2019). “Assessing binge-watching behaviors: Development and validation of the "Watching TV Series Motives" and "Binge-Watching Engagement and Symptoms" questionnaires", Computers in Human Behavior, Vol. 90, pp. 26-36. 
Forchtner, B., and Tominc, A. (2017). "Kalashnikov and cooking-spoon: Neo-Nazism, veganism and a lifestyle cooking show on YouTube", Food, Culture \& Society. Vol. 20 No. 3, pp. 415-441.

Ford, E. A., Roman, S. D., McLaughlin, E. A., Beckett, E. L., and Sutherland, J. M. (2020). "The association between reproductive health smartphone applications and fertility knowledge of Australian women", BMC Women's Health. Vol. 20 No. 1, pp. 1-10.

Foster, A., and Ford, N. (2003). "Serendipity and information seeking: an empirical study", Journal of Documentation, Vol. 59 No. 3, pp. 321-340. https://doi.org/10.1108/00220410310472518.

Foster, D. (2020). Factors influencing the popularity of YouTube videos and users' decisions to watch them. University of Wolverhampton, UK (PhD thesis). https://wlv.openrepository.com/handle/2436/623742

Gill, R., and Orgad, S. (2018). "The amazing bounce-backable woman: Resilience and the psychological turn in neoliberalism", Sociological Research Online. Vol. 23 No. 2, pp. 477-495.

Gruet, S. (2021). "Zoella and the exam board masturbation row", BBC News. https://www.bbc.co.uk/news/newsbeat-55889311

Haimson, O. L., Carter, A.J., Corvite, B. W., Wang, B., Liu, T, and Lige, A. (2021). "The major life events taxonomy: Social readjustment, social media information sharing, and online network separation during times of life transition", Journal of the Association for Information Science and Technology. https://doi.org/10.1002/asi.24455

Harisanty, D. (2019), "Senior high school students' use of library resources and services", Library Philosophy and Practice. Paper 3021. https://digitalcommons.unl.edu/libphilprac/3021/

$\mathrm{Hu}, \mathrm{X}$., Lee, J. H., and Wong, L. K. Y. (2010), "Music information behaviors and system preferences of university students in Hong Kong", Journal of Academic Librarianship, Vol. 36 No. 1, pp. 63-69.

Li, H. O. Y., Bailey, A., Huynh, D., and Chan, J. (2020). "YouTube as a source of information on COVID-19: a pandemic of misinformation?", BMJ Global Health. Vol. 5 No. 5, paper e002604.

Lloyd, A., and Olsson, M. (2019). "Untangling the knot: The information practices of enthusiast car restorers", Journal of the Association for Information Science and Technology. Vol. 70 No. 12, pp. 1311-1323.

Macleod, M., and Anderson, A. S. (2018). "Cancer prevention - the feasibility and acceptability of promoting breast cancer risk reduction in the screening setting through a lifestyle magazine", European Journal of Cancer Care. Vol. 27 No. 2, paper e12823.

Mafra, A. L., Varella, M. A. C., Defelipe, R. P., Anchieta, N. M., de Almeida, C. A. G., and Valentova, J. V. (2020). "Makeup usage in women as a tactic to attract mates and compete with rivals", Personality and Individual Differences. Vol. 163, pp. 110042.

Mardon, R., Molesworth, M., and Grigore, G. (2018). "YouTube Beauty Gurus and the emotional labour of tribal entrepreneurship", Journal of Business Research, Vol. 92, pp. 443-454.

McKenzie, P.J. (2003), "A model of information practices in accounts of everyday-life information seeking", Journal of Documentation, Vol. 59 No. 1, pp. 19-40.

Ocepek, M.G. (2017), "Passive information behaviors while grocery shopping", Proceedings of the Association for Information Science and Technology, Vol. 54 No. 1. pp. 507-510. 
Olsson, M., and Lloyd, A. (2017). "Being in place: embodied information practices", Information Research, Vol. 22 No. 1, http://informationr.net/ir/22-1/colis/colis1601

Pálsdóttir, Á. (2010). "The connection between purposive information seeking and information encountering: A study of Icelanders' health and lifestyle information seeking", Journal of Documentation. Vol. 66 No. 2, pp. 224-244.

Pennock, D. M., Flake, G. W., Lawrence, S., Glover, E. J., and Giles, C. L. (2002). “Winners don't take all: Characterizing the competition for links on the web", Proceedings of the National Academy of Sciences. Vol. 99(8), pp. 5207-5211.

Riboni, G. (2017). "Between professionalism and amateurship: makeup discourse on YouTube", Lingue Culture Mediazioni-Languages Cultures Mediation (LCM Journal), Vol. 4 No. 1, pp. 117-134.

Raun, T. (2018). "Capitalizing intimacy: New subcultural forms of micro-celebrity strategies and affective labour on YouTube", Convergence. Vol. 24 No. 1, pp. 99-113.

Rees, E. (2019). "Television, gas and electricity: Consuming comfort and leisure in the British home 1946-65", The Journal of Popular Television. Vol. 7 No. 2, pp. 127-143.

Robbins, M. L., and Karan, A. (2020). "Who gossips and how in everyday life?", Social Psychological and Personality Science, Vol. 11 No. 2, pp. 185-195.

Savolainen, R. (1995), "Everyday life information seeking: Approaching information seeking in the context of "way of life'", Library \& information science research, Vol. 17 No.3, pp. 259-294.

Schneider, T., and Davis, T. (2010). "Fostering a hunger for health: Food and the self in 'The Australian Women's Weekly'”, Health Sociology Review. Vol. 19 No. 3, pp. 285-303.

Schwemmer, C., and Ziewiecki, S. (2018). "Social media sellout: The increasing role of product promotion on YouTube", Social Media+ Society. Vol. 4 No. 3, paper 2056305118786720.

Small, J. (2017). "Women's "beach body" in Australian women's magazines", Annals of Tourism Research. Vol. 63, pp. 23-33.

Solomon, P. (1997), "Discovering information behavior in sense making. I. Time and timing", Journal of the American Society for Information Science, Vol. 48 No. 12, pp. 1097-1108.

Stubb, C., Nyström, A. G., and Colliander, J. (2019). "Influencer marketing", Journal of Communication Management, Vol. 23 No. 2, pp. 109-122. https://doi.org/10.1108/JCOM-11-2018-0119

Thelwall, M. and Cash, S. (in press). "Bullying discussions in UK female influencers' YouTube comments", British Journal of Guidance and Counselling. https://doi.org/10.1080/03069885.2021.1901263

Thelwall, M., and Wilson, P. (2016). "Mendeley readership altmetrics for medical articles: An analysis of 45 fields", Journal of the Association for Information Science and Technology. Vol. 67 No. 8, pp. 1962-1972.

Thelwall, M. (2021). Word association thematic analysis: a social media text exploration strategy, New York, NY: Morgan \& Claypool.

Wilkinson, D., and Thelwall, M. (2011). "Researching personal information on the public web: Methods and ethics", Social Science Computer Review. Vol. 29 No. 4, pp. 387-401.

Wilson, T.D. (1997), "Information behaviour: an interdisciplinary perspective", Information Processing \& Management, Vol. 33 No. 4 , pp. 551-572.

Windham Stewart, P. (2016). "Creating mother and baby therapy groups in prison: emotional valuation", Psychoanalytic Psychotherapy. Vol. 30 No. 2, pp. 152-163.

Wolf, N. (2001). "The beauty myth: How images of beauty are used against women", New York, NYL HarperPerennial. 
Zappavigna, M. (2019). "The organised self and lifestyle minimalism: Multimodal deixis and point of view in decluttering vlogs on YouTube", Multimodal Communication. Vol. 8 No. 1. https://doi.org/10.1515/mc-2019-0001 